\title{
Chrysin Sensitizes Human Lung Cancer Cells to Tumour Necrosis Factor Related Apoptosis-Inducing Ligand (TRAIL) Mediated Apoptosis
}

\author{
Syed Hassan Mehdi' ${ }^{1,2}$, Md Zafaryab ${ }^{1}$, Sana Nafees ${ }^{1}$, Asad Khan ${ }^{1}$, Irfan Ahmad ${ }^{1}$, \\ Zubair Bin Hafeez ${ }^{1}$, Moshahid Alam Rizvi ${ }^{1}$
}

${ }^{1}$ Department of Biosciences, Jamia Millia Islamia, New Delhi, Department of Biosciences, Jamia Millia Islamia, New Delhi, India. ${ }^{2}$ Institute of Aging, Geriatrics, Division, University of Arkansas for Medical Sciences, Little Rock-72205, USA.

\begin{abstract}
Background: Lung cancer is the primary cause of cancer deaths worldwide. Thus, the requisite for more coherent methods to lung cancer therapy is needed. Purpose: Chrysin (5, 7-dihydroxyflavone) is a naturally occurring flavonoid having a wide range of pharmacological properties and is commonly found in fruits, vegetables, honey and propolis. In our study, we have hypothesized that chrysin would have anticancer activity on L132 lung cancer cell line. Methods: The cytotoxic effects were assessed by MTT and NRU assay. DAPI was used to evaluate the cell death. The pro- or anti-apoptotic proteins were detected by Western Blot assay, and, besides, mRNA expression was analysed with RT-PCR. In silico study of chrysin was performed to identify suitable inhibitors against the protein function. Results: Results indicated that chrysin enhanced the inhibitory effects of TRAIL (Tumour Necrosis Factor Related Apoptosis-Inducing Ligand) in comparison to TNF- $\alpha$ (tumour necrosis factor) on cell viability in L132 lung cancer cells and altered nuclear morphology of cells was observed in DAPI (4',6-diamidino-2-phenylindole) staining after 48 hrs treatment. Treatment with chrysin enhances TRAIL-induced apoptosis by increasing the expression of apoptosis-related proteins including caspase- $3,8,9$ and Bax, whereas the expression of Bcl-2 was decreased. Chrysin was docked with caspase-3, 8, 9, Bax, and Bcl-2 proteins to identify suitable inhibitors against the protein function. Conclusion: We concluded that chrysin sensitizes lung cancer cells to TRAIL-induced apoptosis and may be considered for future studies as a promising therapeutic candidate for human lung cancer.
\end{abstract}

Keywords: Lung cancer- Chrysin- TNF- $\alpha$ - TRAIL- therapeutic action

Asian Pac J Cancer Biol, 4 (2), 27-33

\section{Introduction}

Lung cancer is considered as a big killer among cancer diseases, which signifies a serious risk to human health [1]. Thus, it is essential to explore novel targeted compounds against lung cancer [2]. The flavonoids are plant phenolic compounds and have biochemical and pharmacological properties viz., antibacterial, antiviral, anti-inflammatory, antiallergic, antithrombotic, anti-mutagenic and antineoplastic [3]. Epidemiological studies further validated the significance of flavonoids with a reduced risk of cardiovascular ailment and different types of cancers together with breast, colon, lung, pancreas, oral and prostate both in vitro and in vivo [4].
Submission Date: 05/02/2019 Acceptance Date: 07/03/2019

Chrysin (5, 7-dihydroxyflavone) is a natural flavonoid present in many plant extracts, honey and propolis. It possesses numerous biological and pharmacological properties including antioxidant, apoptotic, anticancer, anti-inflammatory etc. [5]. Recent studies have revealed that chrysin regulates key molecules involved in inflammation, cancer and aging [6]. It has also been reported that chrysin induces apoptosis in cancer cells, making it a possible candidate as anticancer agent [7]. It has been demonstrated that chrysin inhibits the growth of Hela cells via apoptosis and inactivation of AKT in cancer cell lines [8]. It also considerably sensitizes TNF- $\alpha$ induced apoptosis in several human cancer cells [9].

It might be possible that a combinatorial effect of

Corresponding Author:

Dr. Syed Hassan Mehdi, Moshahid Alam Rizvi

Department of Biosciences, Jamia Millia Islamia, New Delhi, Department of Biosciences, Jamia Millia Islamia, New Delhi. Institute of Aging,

Geriatrics, Division, University of Arkansas for Medical Sciences, Little Rock-72205, USA

Email: saeedimam@gmail.com,rizvi_ma@gmail.com 
a chemotherapeutic drug with TRAIL or TNF- $\alpha$ is required to achieve efficient cell death clinically. Currently, much exploration in the field of research is being carried on appraisal of nontoxic and competent plant-based products against cancer because of their constructive outcomes in vivo and in vitro.

In the present study, we have demonstrated that chrysin synergistically enhances the upregulation of gene expressions of caspase-3, 8, 9, Bax, and downregulation of the expression of Bcl-2 in TRAIL resistant lung cancer cells to TRAIL induced apoptosis. Besides TRAIL, TNF- $\alpha$ was also thought to be a potent anticancer agent due to its cytotoxicity against several tumour cell lines. However, the clinical use of TNF- $\alpha$ is limited because of its systemic toxicity. The reason behind this is largely

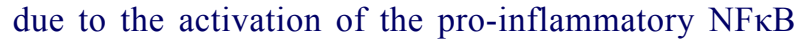
(Nuclear factor Kappa-B) family transcription factors [10-12]. TRAIL and TNF- $\alpha$ individually did not show the significant change in the expression of apoptotic and anti-apoptotic proteins, however, in combination with TRAIL, chrysin showed significant change of expression in apoptotic and anti-apoptotic protein. Additionally, chrysin was docked with caspase-3, 8, 9, Bax and Bcl-2 to identify suitable inhibitors against the protein function. Thus, our findings raise the possibility that combined use of chrysin and TRAIL could be a candidate therapy for the treatment of lung cancer.

\section{Materials and Methods}

\section{Procurement of chemicals}

Chrysin was purchased from Sigma-Aldrich (USA). DMEM (Dulbecco's modified Eagle's medium) powder, Neutral Red, MTT (3-(4,5-dimethylthiazole-2-yl)-2,5 diphenyl tetrazolium bromide) and $0.25 \%$ trypsin and $0.02 \%$ EDTA mixture were purchased from Himedia (India). Fetal bovine serum (FBS) was from Gibco (USA). All the other chemicals and reagents were purchased from Merck and were of molecular biology grade. Chrysin was dissolved in DMSO and stored at $4^{\circ} \mathrm{C}$.

\section{Preparation of cell culture medium}

DMEM with $2 \mathrm{mM}$ L-glutamine and glucose 4.5 gm/L supplied as dry powder was dissolved in 1L Milli-Q water and supplemented with $25 \mathrm{mM} \mathrm{NaHCO}, 10 \mathrm{mM}$ HEPES, thereafter, $1 \%(\mathrm{v} / \mathrm{v})$ antibiotics and antimycotic was added. After that the $\mathrm{pH}$ was adjusted to 7.4 using $1 \mathrm{~N}$ $\mathrm{NaCl}$ or $\mathrm{HCl}$, and medium was filtered sterilize $(0.22 \mu \mathrm{m})$. Incubating the medium at $37^{\circ} \mathrm{C}$ for $72 \mathrm{~h}$ routinely checked the sterility and then the medium was stored at $4^{\circ} \mathrm{C}$. Finally, the complete culture medium was prepared by the addition of Fetal Bovine Serum 10\% (v/v) for maintaining cell lines.

\section{Procurement cell lines and maintenance}

Lung cancer cell lines were procured from NCCS Pune, India. L-132 was cultured and maintained in Dulbecco's Modified Eagle's Medium (DMEM), supplemented with $10 \%$ Fetal Bovine Serum and 1\% antibiotics solution containing penicillin, streptomycin and amphotericin with $25 \mathrm{mM}$ sodium bicarbonate and $10 \mathrm{mM}$ HEPES in a humidified atmosphere of $5 \% \mathrm{CO}_{2}$ at $37{ }^{\circ} \mathrm{C}$ in culture dishes/flasks. Stock culture was maintained in the exponential growth phase by passaging as monolayer culture using in $0.02 \%$ EDTA. The dislodged cells were suspended in complete medium and reseeded routinely.

\section{Cytotoxicity assay}

The cytotoxic effect was assessed in lung cancer cell exposed to different concentrations of chrysin by the MTT assay. 3-(4,5-dimethyl-2-yl)-2,5-diphynyl tetrazolium bromide (MTT) is metabolic substrate, which is reduced by the mitochondrial succinate dehydrogenase enzyme and forms formazan crystal. Cells were seeded overnight at the number of $1 \times 10^{4}$ per well and then incubated with various concentration of chrysin for $48 \mathrm{~h}$. At the end of the treatment, medium was removed, and cells were incubated with $20 \mu$ of MTT $(5 \mathrm{mg} / \mathrm{mL}$ in PBS) in fresh medium $(50 \mu \mathrm{L})$ for $4 \mathrm{~h}$ in $\mathrm{CO}_{2}$ incubator. After four hours formazan crystal, formed by mitochondrial reduction of MTT were solubilized in DMSO (Dimethyl sulfoxide) (150 $\mu \mathrm{L} /$ well) and the absorbance was read at $570 \mathrm{~nm}$ after 10 min incubation on the iMark Microplate Reader (Bio-Rad, USA). Percent of cytotoxicity was expressed as $\mathrm{IC}_{50}[13-14]$.

\section{Neutral red dye uptake assay}

Neutral red (3-amino-m-dimethylamino-2methylphenazine hydrochloride) assay determined the accumulation of the neutral red dye in the lysosomes of viable, uninjured cells. The Chrysin was incubated with cells for $48 \mathrm{~h}$. Neutral red dye $(100 \mu \mathrm{g} / \mathrm{mL})$ was dissolved in serum free medium (DMEM). The $\mathrm{pH}$ of the neutral red solution was adjusted in all the experiments to 6.35 with the addition of $\mathrm{KH}_{2} \mathrm{PO}_{4}(1 \mathrm{M})$. Ten microlitres of neutral red was incubated with the cells for $1 \mathrm{~h}$. After that, washed with phosphate buffer saline (PBS) and added $1 \mathrm{~mL}$ of elution medium (EtOH/AcCOOH, 50\%/1\%) followed by gentle shaking for $10 \mathrm{~min}$ so that complete dissolution was achieved. The absorbance was taken at $540 \mathrm{~nm}$ using iMark Microplate Reader (Bio-Rad, USA). Percent cytotoxicity was expressed as $\mathrm{IC}_{50}[15]$.

\section{DAPI Staining}

Cell nuclear morphology was evaluated by fluorescence microscopy following DAPI staining. L132 cells were treated with chrysin and in combination with TRAIL for 48h. The cells were washed with PBS ( $\mathrm{pH} 7.4$ ), fixed with ice cold $70 \%$ ethanol and resuspended in DAPI, and incubated for $15 \mathrm{~min}$ at $37^{\circ} \mathrm{C}$ wrapped in aluminium foil. The cells were then washed with PBS and examined under Nikon Eclipse fluorescence microscope (Nikon Instruments Inc., NY, and USA [16].

\section{In-silico study of chrysin}

To understand the mechanism of chrysin towards apoptotic/anti-apoptotic gene, molecular docking was carried out for the chrysin using Auto Dock 4.2 [17]. Lamarckian Genetic Algorithm was used to carry out the docking analysis. The docking simulations end 
with multiple runs and cluster analysis of ligands were performed with their corresponding docked energy. The binding sites for these molecules were selected based on the ligand-binding pocket of the templates [18]. Docking solutions with ligands all-atom RMSDs within 2.0 A of each other were clustered together and ranked by the lowest energy representative. Finally, the obtained top-posed docking conformations were subjected to post-docking energy minimization on DS 3.5. The resultant structure files were analyzed using PyMOL visualization programs [19].

\section{Western Blot}

Western blot analysis was carried out according to [20] using cytosolic as well as nuclear fractions of human lung cancer cells L132 treated with selected concentrations of chrysin alone and in combination with TRAIL for $48 \mathrm{~h}$. Protein concentration was determined by using Bradford reagent and lysates were resolved on $15 \%$ sodium dodecyl sulphate (SDS) polyacrylamide gels. The proteins were then electro transferred onto nitrocellulose membrane (Sigma, St. Louis, MO, USA). After blocking with 5\% non-fat milk in Tris-buffered saline (TBS, $0.1 \mathrm{M}, \mathrm{pH} 7.4$ ), blots were subjected to various primary antibody incubations with caspase-3, 8, 9, Bax and Bcl-2 (R \& D System, USA) at $4{ }^{\circ} \mathrm{C}$ overnight. Protein abundance of $\beta$-actin served as a control for protein loading for cytosolic and nuclear fractions, respectively. Membranes were incubated with secondary antibody concerning primary antibody and diluted at an appropriate dilution in $1 \% \mathrm{BSA}$, for $1 \mathrm{~h}$ at room temperature. After each step, blots were washed thrice with Tris-buffer saline-Tween 20 (TBST). Protein bands were detected by enhanced chemiluminescence method (ECL, Bio-Rad, Hercules, CA, USA). The protein expression pattern was obtained by normalizing the density to that of $\beta$-actin for cytosolic and nuclear fractions.

\section{Quantitative Real Time PCR}

Total RNA was isolated from untreated and treated L132 cells with selected concentrations of the chrysin alone and in combination with TRAIL for $48 \mathrm{~h}$ using TRI reagent (Sigma, St. Louis, MO, USA). Complementary DNA (cDNA) was synthesized using the easy cDNA synthesize kit (Bio-Rad, USA). The reaction PCR was performed in a final volume of $20 \mu \mathrm{L}$ containing $10 \mu \mathrm{L}$ Taq premix, $2 \mu \mathrm{L}$ cDNA, $2 \mu \mathrm{L}$ primer (forward and reverse) and water. RT-PCR was started with an initial cycle of reverse transcription at $95{ }^{\circ} \mathrm{C}$ for 4 min followed by 35 cycles of denaturation at $94^{\circ} \mathrm{C}$ for $30 \mathrm{~s}$, annealing $\left(58^{\circ} \mathrm{C}\right.$ for $30 \mathrm{~s})$, and extension $\left(72^{\circ} \mathrm{C}\right.$ for $\left.30 \mathrm{~s}\right)$. The primer sequences used for Cas-3, 8, 9, Fas, Bcl2 and Bax and $\beta$-actin were designed for L132 cells are as follows:

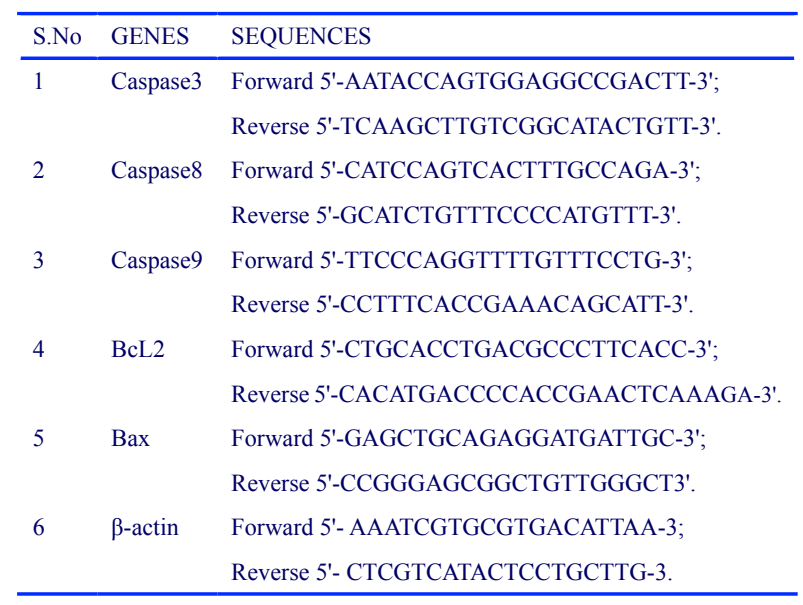

Following amplification, the PCR products were electrophoresed in a $2 \%$ agarose gel.

\section{Statistical analysis}

Data were analyzed using Microsoft Excel (Microsoft, Redmond, USA). Results are expressed as mean \pm standard deviation. The difference between each experimental group and the control group was analyzed with Student's t-test. Probability values of less than 0.05 were considered statistically significant.

\section{Results}

Chrysin sensitizes lung cancer cells for TRAIL induced cytotoxicity but not for $T N F-\alpha$

The cytotoxic effect was assessed by the MTT and NRU assay in L132, which were exposed to different concentrations of chrysin. Results indicate that chrysin alone is not inducing cytotoxicity in lung cancer cells even at higher concentration (Figure 1). Also, treatment with TRAIL and TNF- $\alpha$ alone $(50-100 \mathrm{ng} / \mathrm{mL})$ also did not show any significant effect on cell viability on L132 cell line (Figure 2).

However, we found that cytotoxic effects of chrysin was increased when we treated the cancer cells in combination with TRAIL whereas, treatment in combination with

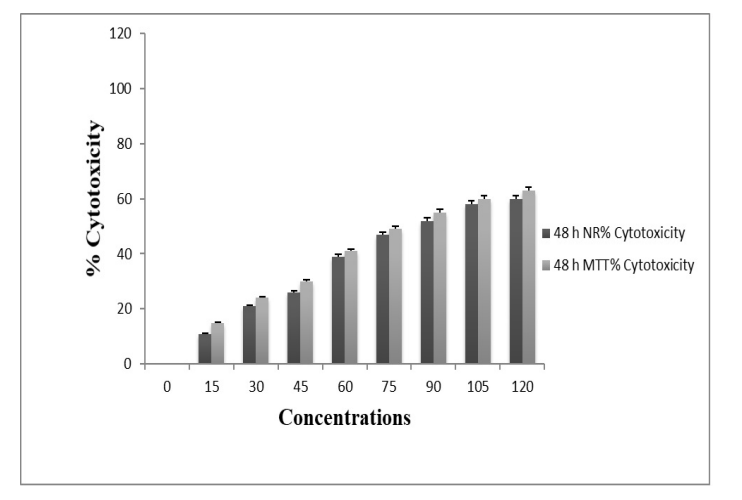

Figure 1. Cytotoxic Effect of Chrysin on Lung Cancer Cell (L132) Treated with Different Concentrations at $48 \mathrm{hrs}$ by MTT and NRU Assay. Values were expressed as mean $\pm \mathrm{SD}$, and the experiment was performed in triplicate $(\mathrm{p}<0.05)$. 
Table 1. The Binding of Chrysin to the Respective Amino acids Sequence of Proteins

\begin{tabular}{lcc}
\hline Compound & Protein & Binding Amino Acids and Position \\
\hline Chrysin & Bcl-2 & Asparagine-102 \\
& & Arginine-105 \\
& & Tyrosin- 67 \\
& Bax & Glycine-26 \\
& & Glutamine-73 \\
& Caspase 9 & Glutamine-154 \\
& & Glutamic Acid-297 \\
& Caspase 3 & Methionine-39 \\
& & Tyrosine-37 and 276 \\
& Caspase 8 & Isoleucin-154 \\
& & Lysine-409 \\
\hline
\end{tabular}

TNF- $\alpha$ did not show any significant toxicity on lung cancer cell line as shown in Figure 3. Chrysin enhanced the inhibitory effects of TRAIL on cell viability in L132 lung cancer cells within $48 \mathrm{~h}$ dose- dependently.

\section{Chrysin induced cell apoptosis through DAPI staining}

Cell death was confirmed through the fluorescence microscopic study. Results showed that the cells treated with chrysin and in combination with TRAIL 48h showed altered nuclear morphology. Control cells showed normal/regular morphology, however in chrysin and TRAIL treated cells; nuclear morphology seems to have more nuclear condensation, nuclear blebbing, nuclear fragmentation and overall morphological changes as shown in Figure 4.

\section{Expression of apoptotic marker proteins by western blotting}

The expression of apoptotic and anti-apoptotic proteins was confirmed through the western blot analysis by using protein specific monoclonal antibody. We found that chrysin treated cells showed upregulation of apoptotic marker proteins viz; Bax, Caspases-3, 8 and 9 and down-regulation of anti-apoptotic protein, Bcl-2 when treated in combination with TRAIL than treated

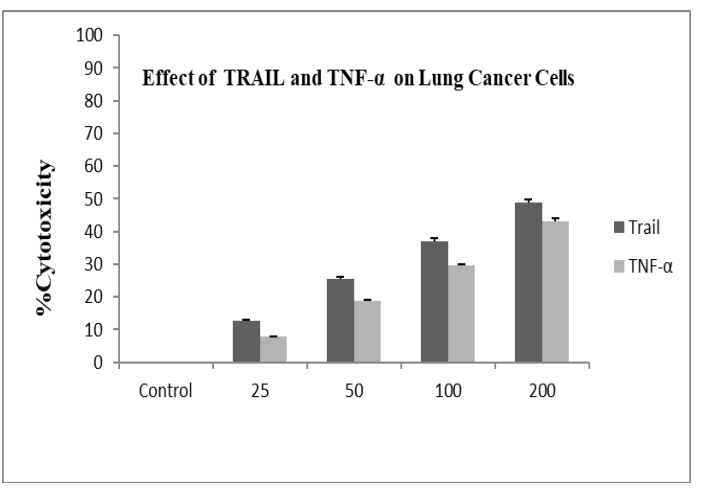

Figure 2. Cytotoxic Effect of Trail and TNF- $\alpha$ on on Lung Cancer Cell (L132) Treated with Different Concentrations at $48 \mathrm{hrs}$ by MTT Assay. Experiment was performed in triplicate $(\mathrm{p}<0.05)$.

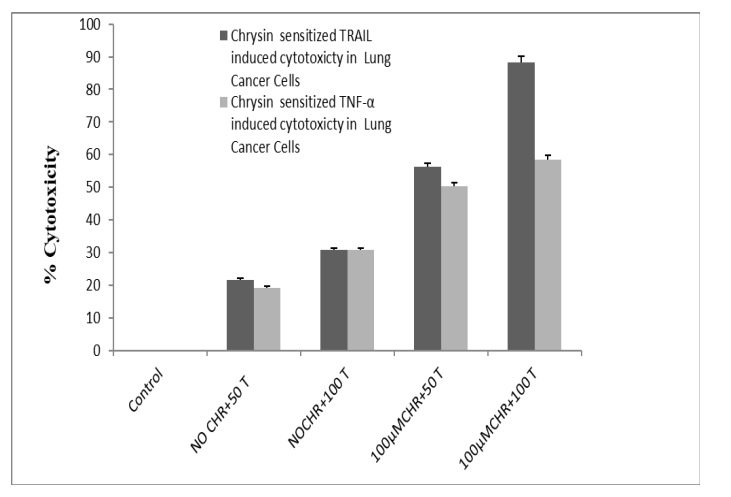

Figure 3. Chrysin Sensitized Trail and TNF- $\alpha$ Cytotoxicity on on Lung Cancer Cell (L132) Treated with Different Concentrations at $48 \mathrm{hrs}$ by MTT Assay. Experiment was performed in triplicate $(\mathrm{p}<0.05)$.

alone, as shown in Figure 5. Our data shows that treatment with chrysin enhances TRAIL-induced apoptosis by increasing the expression of apoptosis-related proteins including caspase-3, 8, 9 and Bax, whereas by decreasing the expression of Bcl-2. However, we did not find any significant effect on the expression of these genes when we treated the cells with chrysin and TNF- $\alpha$ in combination (data not shown).

Chrysin augments TRAIL-induced apoptosis through activation of caspases and Bcl-2 family members

We performed quantitative real time PCR to analyze the extrinsic and intrinsic apoptotic pathways in chrysin, TRAIL induced apoptosis individually and in combination with TRAIL. We found that the genes viz., caspase-3, 8, 9, Bax are upregulated whereas Bcl-2 was found to be downregulated in chrysin, TRAIL individually and in combination with TRAIL in L132 as shown in Figure 6.

In silico study of chrysin on apoptotic and anti-apoptotic proteins

Molecular docking of chrysin with Bax, Bcl-2, caspase-3, caspase- 8 and caspase- 9 were performed through latest version of Vina tool. Chrysin bind to the

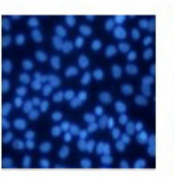

$\mathrm{L} 132 \mathrm{CNT}$

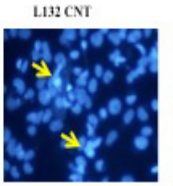

L.132 CHR 40-TRAII.

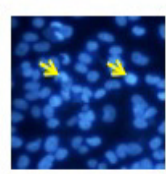

L-132CHR 20

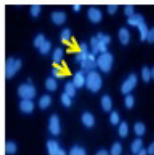

L.132CHR 80

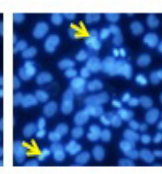

L-132 CHR 20-TRAIL

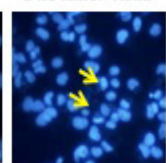

L.132 CHR 80+ TRAIL.

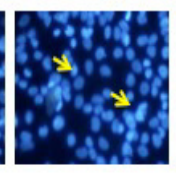

L.132 CHR 40
Figure 4. Microscopic Appearance of Chrysin and Its Combination with Trail Treated Lung Cancer Cells (L132). Fluroscence microscope photographs of L132 cells treated for $48 \mathrm{hrs}$ and stained with DAPI (magnification 40x). 


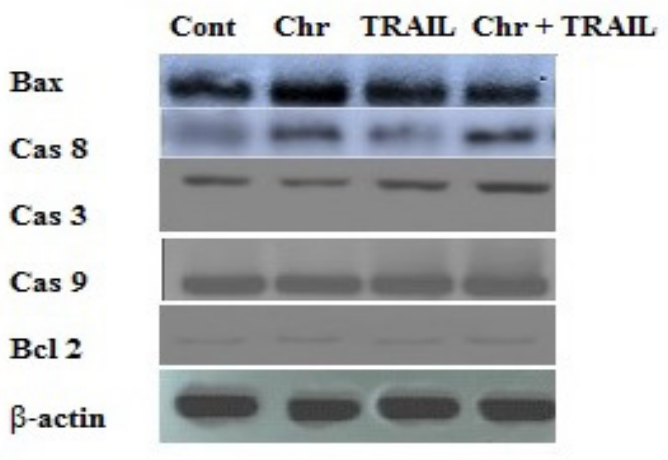

Figure 5. Immunoblotting Showing the Effect of Chrysin and Its Combination with TRAIL Induced Caspase-3, Caspase-9, Caspase-8, Bax and Bcl-2 Expression in Human Lung Cancer Cells

apoptotic and anti-apoptotic proteins via different amino acids. The detail of chrysin binding with amino acids and their position is summarized in Table 1 and Figure 7.

\section{Discussion}

Cancer is a complex disease; abnormal intracellular signal transduction system is connected to the occurrence and progression of cancer cells. Chemotherapy is one of the basic approaches to the treatment of cancer. Conversely, the chemotherapeutic drugs currently used for treating different types of cancer have adverse side effects. Thus, recent research is primarily focused on herbal plants that have been studied for being nontoxic and for the treatment and prevention of cancer [21].

The anti-cancer property of chrysin has been described earlier. The effect of chrysin on cell viability elucidated that chrysin possesses potent in vitro anti-cancer activity. The results obtained from the MTT and NRU assays indicated that lung cancer line (L132) showed time and dose dependent viability loss by the addition of chrysin. Chrysin has been reported to induce apoptosis in a numerous cancer cell lines, as well as HeLa, cervical cancer cells [22], U937, HL-60 and L1210 leukemia cells [23-25], OE33 oesophageal adenocarcinoma cells [26] and KYSE-510 oesophageal squamous carcinoma

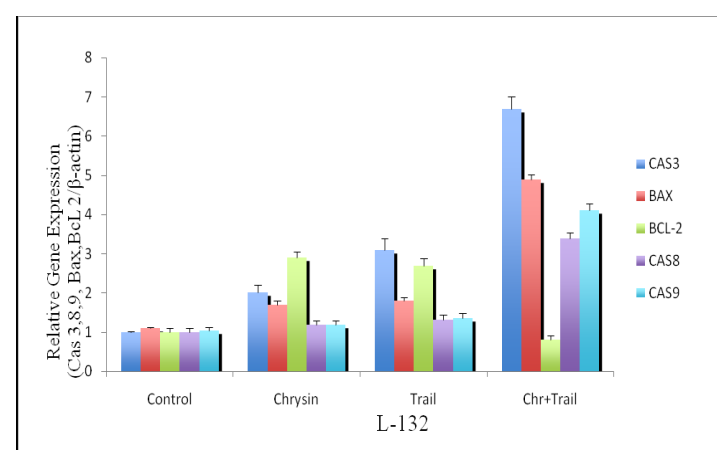

Figure 6. Quantitative Real Time PCR Showing the effect of Chrysin on TRAIL Induced Caspase-3, Caspase-9, Caspase-8, Bax and Bcl-2 Expression in Human Lung Cancer Cells.

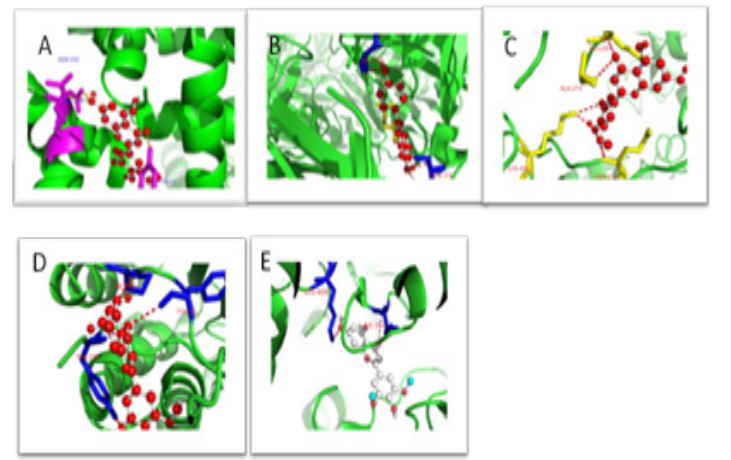

Figure 7. A-E Showed the Complex Structures of Dock Proteins with Chrysin.

cells [27]. In the present study, we attempted to further address the anti-cancer potential of chrysin by evaluating the sensitization effect of chrysin on TNF- $\alpha$ and TRAIL induced apoptotic cell death and the molecular mechanisms involved.

According to the studies conducted by [28] it has been evaluated that TRAIL selectively kills various types of cancer cells without affecting normal cells, but TRAIL resistance has been recurrently observed in cancerous cells. It was demonstrated previously that chrysin sensitizes A549 and HeLa human cancer cell lines to TRAIL-induced apoptosis.

TRAIL is a potent inducer of apoptosis in cancerous cells. Several studies demonstrated that most of the cancerous cells are resistant to TRAIL-induced death, but combinatorial approaches based on TRAIL and different chemotherapeutic compounds like small-molecule inhibitors, drugs, and natural compounds, have been developed to overwhelm the resistance of cancer cells to TRAIL [29]. Therefore, in order to evade tumour cell resistance to TNF and TRAIL, combinatorial therapies are desirable.

Our results demonstrated that TRAIL individually did not show a significant change in the expression of apoptotic and anti-apoptotic proteins, however, in combination with TRAIL, chrysin showed significant change of expression in apoptotic and anti-apoptotic protein. In earlier studies it was reported that chrysin promotes TRAIL-induced caspase activation in CNE1 nasopharyngeal cancer cells [30]. Activation of caspases plays a significant role in a programmed cell death generated by different stimuli. Caspase- 8 activates caspase- 9-mediated apoptotic pathway through cleavage of Bid and then activate caspase-3 by cleavage of procaspase-3 [31]. Chrysin sensitizes tumour cells to TRAIL induced apoptosis in our study as well. Chrysin exhibits strong cytotoxic effect in combination with TRAIL on lung cancer cells. TRAIL-mediated apoptotic pathways could be a target of the anticancer efficacy of chrysin in lung cancer cells. We found that combined treatment of chrysin with TRAIL enhances the upregulation of caspase-3, 89 and Bax and downregulation of Bcl-2 in treated cells. The results indicate that chrysin in combination with TRAIL is a potentially upregulated and downregulated the 
expression of genes. Real-time PCR showed that chrysin upregulated the gene expression of caspase-3, 8, 9, Bax and downregulated the expression of Bcl-2 individually and in combination with TRAIL in L132 cells. Chrysin was docked with caspase-3, 8, 9, Bax and Bcl-2 to identify suitable inhibitors against the protein function. Thus, chrysin interacts with the target can be used as a potent inhibitor to block the action of protein viz., caspase-3, 8, 9, Bax and Bcl-2. Outcomes from our study thus demonstrated a novel function of chrysin and augmented the significance of chrysin as a useful chemotherapeutic compound.

In conclusion, our results revealed that combinatorial treatment of chrysin with TRAIL considerably augments apoptosis in lung cancer cells via Bcl-2 and caspases-dependent apoptotic pathway. Further investigation is needed to dichotomize the link among the above mechanisms. Hence, these results propose that combinatorial treatment of chrysin with TRAIL could be an effective strategy for human lung cancer therapy.

\section{Acknowledgements}

The authors would like to acknowledge the University Grants Commission (India) DS Kothari Fellowship (Grant Number: 4-2/2006 (BSR)/BL/13-14/0190) for providing the financial assistance.

\section{Competing Interests}

Authors declare that they have no competing interests.

\section{References}

1. Zhang Y, Xu X, Li W, Miao H, Huang S, Zhou Y, et al. Activation of endoplasmic reticulum stress and the extrinsic apoptotic pathway in human lung cancer cells by the new synthetic flavonoid, LZ-205. Oncotarget. 2016;7(52):8725770.

2. Scagliotti GV, Parikh P, von Pawel J, Biesma B, Vansteenkiste J, Manegold C, et al. Phase III study comparing cisplatin plus gemcitabine with cisplatin plus pemetrexed in chemotherapy-naive patients with advanced-stage nonsmall-cell lung cancer. Journal of clinical oncology : official journal of the American Society of Clinical Oncology. 2008;26(21):3543-51.

3. Nafees S, Rashid S, Ali N, Hasan SK, Sultana S. Rutin ameliorates cyclophosphamide induced oxidative stress and inflammation in Wistar rats: role of NFkappaB/MAPK pathway. Chemico-biological interactions. 2015;231:98-107.

4. Rashid S, Nafees S, Vafa A, Afzal SM, Ali N, Rehman MU, et al. Inhibition of precancerous lesions development in kidneys by chrysin via regulating hyperproliferation, inflammation and apoptosis at pre clinical stage. Archives of biochemistry and biophysics. 2016;606:1-9.

5. Pushpavalli G, Veeramani C, Pugalendi KV. Influence of chrysin on hepatic marker enzymes and lipid profile against D-galactosamine-induced hepatotoxicity rats. Food and chemical toxicology : an international journal published for the British Industrial Biological Research Association. 2010;48(6):1654-9.

6. Shin EK, Kwon HS, Kim YH, Shin HK, Kim JK. Chrysin, a natural flavone, improves murine inflammatory bowel diseases. Biochemical and biophysical research communications. 2009;381(4):502-7.

7. Yang F, Jin H, Pi J, Jiang JH, Liu L, Bai HH, et al. Anti-tumor activity evaluation of novel chrysin-organogermanium(IV) complex in MCF-7 cells. Bioorganic \& medicinal chemistry letters. 2013;23(20):5544-51.

8. Miyamoto S, Kohno H, Suzuki R, Sugie S, Murakami A, Ohigashi H, et al. Preventive effects of chrysin on the development of azoxymethane-induced colonic aberrant crypt foci in rats. Oncology reports. 2006;15(5):1169-73.

9. Li X, Huang Q, Ong CN, Yang XF, Shen HM. Chrysin sensitizes tumor necrosis factor-alpha-induced apoptosis in human tumor cells via suppression of nuclear factor-kappaB. Cancer letters. 2010;293(1):109-16.

10. Feinberg B, Kurzrock R, Talpaz M, Blick M, Saks S, Gutterman JU. A phase I trial of intravenously-administered recombinant tumor necrosis factor-alpha in cancer patients. Journal of clinical oncology : official journal of the American Society of Clinical Oncology. 1988;6(8):1328-34.

11. Karin M, Lin A. NF-kappaB at the crossroads of life and death. Nature immunology. 2002;3(3):221-7.

12. Aggarwal BB. Signalling pathways of the TNF superfamily: a double-edged sword. Nature reviews Immunology. 2003;3(9):745-56.

13. Mehdi SH, Qamar A. Paraquat-induced ultrastructural changes and DNA damage in the nervous system is mediated via oxidative-stress-induced cytotoxicity in Drosophila melanogaster. Toxicological sciences : an official journal of the Society of Toxicology. 2013;134(2):355-65.

14. SH. M, A. Q, Zafaryab M ea. Malathion induced cell injury and cell death in the nervous system via oxidative stress induced cytotoxicity in Drosophila melanogaster. Int J Sci Res (2017);6 ((12) ):447-50.

15. Kumar A, Zafaryab M, Umar A, Rizvi MM, Fouad H, Ansari ZA, et al. Relief of Oxidative Stress Using Curcumin and Glutathione Functionalized $\mathrm{ZnO}$ Nanoparticles in HEK293 Cell Line. Journal of biomedical nanotechnology. 2015;11(11):1913-26.

16. Khan MA, Zafaryab M, Mehdi SH, Ahmad I, Rizvi MM. Characterization and anti-proliferative activity of curcumin loaded chitosan nanoparticles in cervical cancer. International journal of biological macromolecules. 2016;93(Pt A):242-53.

17. Aneja B, Irfan M, Hassan MI, Prakash A, Yadava U, Daniliuc CG, et al. Monocyclic beta-lactam and unexpected oxazinone formation: synthesis, crystal structure, docking studies and antibacterial evaluation. Journal of enzyme inhibition and medicinal chemistry. 2016;31(5):834-52.

18. Muthuswamy U AC, Kuppusamy A, et al In Silico Docking studies of Aldose Reductase Inhibitory activity of selected Flavonoids. . Int J Drug Develop Res, . (2012).4 ((3),): 328-34.

19. Chang MW, Ayeni C, Breuer S, Torbett BE. Virtual screening for HIV protease inhibitors: a comparison of AutoDock 4 and Vina. PLoS One. 2010;5(8):e11955.

20. Lee KS, Kim SR, Park HS, Jin GY, Lee YC. Cysteinyl leukotriene receptor antagonist regulates vascular permeability by reducing vascular endothelial growth factor expression. The Journal of allergy and clinical immunology. 2004;114(5):1093-9.

21. Samarghandian S NM, Mohammadi G . Role of caspases, Bax and Bcl2 in Chrysin induced Apoptosis in the A549 human lung adenocarcinoma epithelial cells, . Anticancer Agents Med Chem, . (2014);14, :901-9.

22. Zhang T, Chen X, Qu L, Wu J, Cui R, Zhao Y. Chrysin and its phosphate ester inhibit cell proliferation and induce apoptosis in Hela cells. Bioorganic \& medicinal chemistry. 
2004;12(23):6097-105.

23. Monasterio A, Urdaci MC, Pinchuk IV, Lopez-Moratalla N, Martinez-Irujo JJ. Flavonoids induce apoptosis in human leukemia U937 cells through caspase- and caspase-calpaindependent pathways. Nutrition and cancer. 2004;50(1):90100 .

24. Woo KJ, Jeong YJ, Park JW, Kwon TK. Chrysin-induced apoptosis is mediated through caspase activation and Akt inactivation in U937 leukemia cells. Biochemical and biophysical research communications. 2004;325(4):1215-22.

25. Cipak L, Rauko P, Miadokova E, Cipakova I, Novotny L. Effects of flavonoids on cisplatin-induced apoptosis of HL-60 and L1210 leukemia cells. Leukemia research. 2003;27(1):65-72.

26. Zhang Q, Zhao XH, Wang ZJ. Flavones and flavonols exert cytotoxic effects on a human oesophageal adenocarcinoma cell line (OE33) by causing G2/M arrest and inducing apoptosis. Food and chemical toxicology : an international journal published for the British Industrial Biological Research Association. 2008;46(6):2042-53.

27. Zhang Q, Zhao XH, Wang ZJ. Cytotoxicity of flavones and flavonols to a human esophageal squamous cell carcinoma cell line (KYSE-510) by induction of G2/M arrest and apoptosis. Toxicology in vitro : an international journal published in association with BIBRA. 2009;23(5):797-807.

28. Lirdprapamongkol K, Sakurai H, Abdelhamed S, Yokoyama S, Athikomkulchai S, Viriyaroj A, et al. Chrysin overcomes TRAIL resistance of cancer cells through Mcl1 downregulation by inhibiting STAT3 phosphorylation. International journal of oncology. 2013;43(1):329-37.

29. Voelkel-Johnson C. Combination therapy with TRAIL: Recent developments and potential pitfalls. Cancer biology \& therapy. 2009;8(1):81-3.

30. Li X, Wang JN, Huang JM, Xiong XK, Chen MF, Ong CN, et al. Chrysin promotes tumor necrosis factor (TNF)-related apoptosis-inducing ligand (TRAIL) induced apoptosis in human cancer cell lines. Toxicology in vitro : an international journal published in association with BIBRA. 2011;25(3):630-5.

31. Lan Y, Liu X, Zhang R, Wang K, Wang Y, Hua ZC. Lithium enhances TRAIL-induced apoptosis in human lung carcinoma A549 cells. Biometals : an international journal on the role of metal ions in biology, biochemistry, and medicine. 2013;26(2):241-54.

\section{(c) (i) (8)}

This work is licensed under a Creative Commons AttributionNon Commercial 4.0 International License. 